\title{
Globalization and Consumer Behavior: Global Marketing Strategies Implication- Homogeneity and Heterogeneity (Preliminary Study)
}

\author{
Hossein Nezakati* Maryam Akhoundi \\ Universiti Putra Malaysia (UPM), Malaysia \\ *hossein@econ.upm.edu.my
}

\begin{abstract}
This research aims to explore consumer behavior and their responses to possible effects of globalization, resulting in adopting different global marketing strategies in an Asian country particularly Malaysia which is so different of European ones, especially, in terms of cultural aspects. Homogeneity and heterogeneity in consumer behavior are the main approaches of this research. Rather than causes hindering the possible phenomena of two-polarity of world economy or empires, to find out companies global marketing strategies are the research objectives. So, this research examines data collected through, respectively, qualitative and quantitative methods and addresses companies' marketers and consumers. However, due to innumerous affecting variables and multidimensional nature of globalization, at this point of study there is no absolute evidence to show results but the theoretical assumptions on companies' tendency toward standardization or customization strategies.
\end{abstract}

Keywords: Globalization, Consumer behavior, Global marketing strategies, Standardization, Customization

\section{Introduction}

There is no doubt that consumer behavior; especially for a consumer-centered marketing, is a significant determinant in adopting an organization's marketing strategy and its performance in the hypercompetitive environment of global market. It is implied in marketing concept suggesting an organization should satisfy consumer needs and wants to make profits. To realize this concept, organizations must understand their customers to provide products and services that their customers may purchase and use appropriately. The dynamics of consumer behavior makes it difficult, because the thinking, feelings, and actions of a consumer whether individually or in a group and a society at large are constantly changing. The fact that consumers and their environments are constantly changing highlights the importance of ongoing consumer behavior research and analysis (Kolb, 2008). On the other hand, the multidimensional effects of globalization on consumer behavior and environments have dramatic consequences for market and marketing strategies. The increase in the world trade, an increasing integration of the world's major economies, and the onward march of globalization, will mean that decisions on marketing strategies: standardization and adaptation will continue to be an important issue for academic research and marketing practice (Viswanathan \& Dickson, 2007). Over the last decades, the influence of the globalization tendency on marketing strategies: standardization and adaptation or customization has dominated this literature and remained a controversial topic for scholars and practitioners. As Zou and Cavusgil (2002) points out there is a major gap in this literature of generally accepted conceptualization of global marketing strategy. Hence, the increasing significance of marketing strategies on organizations' performance and the growing effects of globalization on consumer behavior and their response and attitudes towards it put companies in a dilemma of adopting standardization or customization strategies. Considering different approaches: homogeneity and heterogeneity in consumer behavior, this research attempts to keep its unbiased view to examine consumer behavior affected by their own culture, value and in global market; and how these affecting elements lead firms to adopt different marketing strategies: standardization and customization.

\section{Literature Review}

Globalization, a term coined by Levitt (1983), refers to a "new commercial reality". As a result of technology, differences in national or regional preferences were gone and "the world's needs and desires have been irrevocably homogenized, because consumers were expected to prefer standard products of high quality and low price as compared to more customized high price products. An early approach to find a consumer segment with identifiable characteristics was taken by Engledow, Thorelli, and Becker (1975), who identified homogeneous cross-cultural elite of affluent and information-sensitive consumers. Kale and Sudharshan's model (1987) capitalized on similarities across groups of consumers in different 
countries and resulted in a product-class specific framework for identifying strategically equivalent segments. Their objective was to group worldwide consumers that responded to firms' Marketing mix similarly. Kreutzer (1988) proposed a two-step segmentation process in search of a standardized approach. First, countries were segmented on variables deemed important for standardization. These included technological; ecological; socio-cultural; economic; and political-legal criteria. As a consequence, convergence has been considered as a "merely persistent myth of international Marketing" (de Mooij and Hofstede, 2002). Levitt has acknowledged that the globalization trend coexisted with the opposite reality of heterogeneity, fragmentation and parochialism: "the more powerfully homogenized and relentlessly globalized the world's communications and commerce get, the more varied its products and more numerous its consuming segments seem to become" (Levitt, 1988). Waters (2000) distinguished three possible types of world-system: (1) World-empires, in which multiplicities of cultures are unified under the domination of a single government (2) World-economies, in which a multiplicity of political states, each typically focusing on a single culture ('nation-states'), are integrated by a common economic system; the modern world system integrated by a single capitalist economy (which includes state-socialist societies), and (3) World-socialism, in which both the nation-state and capitalism disappear in favor of a single, unified political-economic 36 trading places: the international economy system which integrates a multiplicity of cultures.

"The theoretical foundations of the standardization debate center on the perception of consumer homogeneity and/or the movement toward homogeneity" (Ryans et al. (2003). Globalization is leading to homogenization and convergence in organizations' strategies, structures and processes and in consumer choice (Gachunga, 2008). Zou and Cavusgil (2002) found three strategic perspectives: integration, configuration and standardization. Jain (1989) proposed that standardization strategy would be more effective if worldwide customers, not countries, were the basis of identifying the segment to serve. Opponents to standardization, however, believed that culture maintains a powerful influence on buying behavior, and that apparent homogeneity of preferences might hide differences in several aspects of consumer behavior (Walters, 1986; Usunier, 1996; Belk, 1996; Manrai and Manrai, 1996). Kotler (1986) recognized that standardization could be justified in some circumstances but alerted that "many of the most notable international product failures have come from a lack of product adaptation". He considered customers' buying behavior and resources as leading consumers to be interested in different product features necessitating customization. Country-by-country segmentation was deemed inadequate since it did not allow the identification of segments that transcended national borders (Hassan and Samli, 1994). Thus, advocates of globalization proposed that effective international segmentation meant identifying global segments (ter Hofstede, Steenkamp and Wedel, 1999; Hassan, Craft and Kortam, 2003). According to this view "a global market segmentation strategy should serve as the conceptual link and action mechanism that provides substance and rationale to striking a tradeoff between the two indispensable global strategy ends of standardization and adaptation" (Hassan, Craft and Kortam, 2003).

Douglas and Wind (1987), who disagreed with the idea that an effective global strategy meant standardization of products and brands believing, instead, that there was a 'continuum' of options from 'pure standardization' to 'pure differentiation'. They acknowledged the existence of some global segments in industrial and in consumer markets but argued that these segments were insufficient grounds for complete standardization. They concluded that global standardization was "appropriate only in relation to certain product markets or market segments under certain market environment conditions and dependent on company objectives and structure". The degree of standardization should be higher in markets with similar customer behavior and lifestyle and the higher the product's cultural compatibility (Jain, 1989). Shoham (1995) held that standardization/adaptation should be the result of a sequence of decision-making steps. Recent cross-national consumer empirical studies seem to have left the standardization debate behind; rather, their theoretical justification is in the need to understand the impact of cultural differences on consumer behavior. The existence of similarities among market segments in different cultures, the appropriateness of standardized marketing would also depend on evidence of culturally independent relevant consumer behavior (LeBlanc and Herndon, 2001). The model developed by Hofstede explains most of the variation of consumption and consumer behavior across countries and enables marketing executives to quantify the effects of culture. (De Mooij, 2003).

Conceptual Model \& Hypotheses: As proposed in a conceptual model, on one side consumer behavior is affected by an internal factor including local culture and on the other side, it is influenced by external factors resulted from globalization such as communication, information, interaction, and so on (see figure.1). It is important to mention that consumer behavior serves as an influential factor for 
organization decision-making including marketing strategies. So it can be concluded that in a relationship among globalization, consumer behavior and marketing strategies for a global consumer-centered marketing, globalization as an independent variable, consumer behavior as a mediating variable, culture, values and so on as moderating variables influence global marketing strategy as a dependent variable which in turn via advertising may affect on consumer behavior. As a result, when an organization tends toward product-centered marketing, global marketing strategy would be a mediating variable between globalization and consumer behavior that may lead to homogeneity in consumer behavior by adopting standardization strategy and advertising, in case, culture and or other variables fail in mediating global effects. Research objectives include understanding consumer behavior and their responses to globalization (homogeneity or heterogeneity in consumer behavior), the influence of culture, values and consumption pattern on consumer behavior, and determining global marketing strategies (standardization, customization, or between them). Going through the affecting elements on the area of this study, the research finds a couple of hypotheses. For the purpose of this preliminary study, two following hypothesis are proposed:

H1: There is a significant relationship between consumer behavior homogeneity and marketing strategy standardization.

$\mathrm{H} 2$ : There is a significant relationship between consumer behavior heterogeneity and marketing strategy customization.

Figure 1: Globalization and Consumer Behavior: Global Marketing Strategies Implication Homogeneity and Heterogeneity.

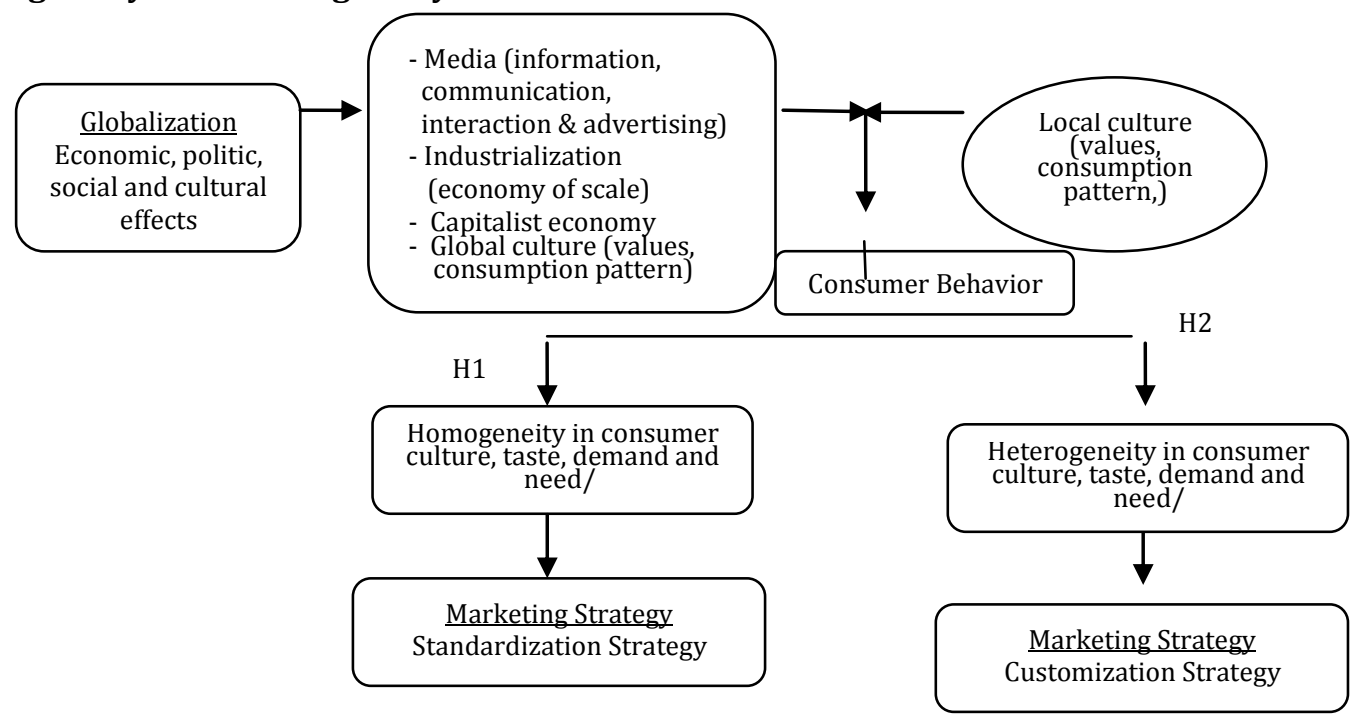

\section{Methodology}

In order to find out the relationship between globalization and consumer behavior and their implications for global marketing strategies, this research will examine data collected through, respectively, qualitative and quantitative methods, given the research approach toward companies' marketers and consumer. At first, through an interview it deals with companies' marketers or strategists to find out their view points and approaches to this phenomena. So, the qualitative method contains semi-structured interview and a questionnaire, as well as literature review gathered from electronic and physical versions of the literature. At second, through a quantitative method and based on the research questionnaire, this study gathers consumers' views as the respondents. The evidence of this study is gathered from Malaysia. The sample is selected based on Sue Greener (2008) attitude who believes the sample size must be more than 30 and less than 1000, therefore this study uses the formula of "Number of samples for an infinitely large population" and selects 500 respondents as sample. In this study like other social studies to determine the number of random samples needed for a $95 \%$ as confidence interval. The sampling design for this study is multistage in which, as it is provided by Creswell (2010), the researcher first identifies clusters (groups) and then samples within them. Companies study firstly concerns the selection of the specific ones to be studied due to their differently adopted strategies towards global markets. Therefore, they are selected systematically. Questionnaires will be mailed to respondents and entered computer database, 
using SPSS program. Based on the theoretical model, a number of factors will be analyzed: a factor indicating homogeneous behavior of consumer in global environment, affecting global marketing strategy and a factor dealing with heterogeneous behavior of consumer in global environment but under effects of local culture which in turn influence the adopted global marketing strategy. Measuring all these constructs reliability, the analysis results will be presented in a matrix structure. In case, these constructs are considered to have strong reliability and validity, our developed model will be confirmed.

\section{Discussion}

Globalization, regardless of its good or bad consequences, has both direct and mediating effects on various spheres including socio-cultural aspects that affect on consumer behavior, and consequently on global marketing strategies. This study partly focuses on consumer behavior to understand their responses and partly on marketers as an important element that handles the companies' strategies and performances in global market. Their strategies shape the incoming global market in which some economies and cultures might be overshadowed by others who are the actors of this market. So, going beyond the economic issues, this study most probably arises many questions in different spheres. Rather than culture there may be other causes like consumer value, life style, government regulations and trade policy to hinder the possible phenomena of two-polarity of world economy or empires. In contrast, some causes such as global pattern of consumption as an influential leverage may facilitate standardization strategy. However, due to innumerous affecting variables and multidimensional nature of globalization, at this point of study there is no absolute evidence to show results, but the theoretical assumptions on companies' tendency towards standardization or customization strategies. This research proposes a broad study on a great sample for precise, realistic results.

\section{References}

Belk, R. (1996). Hyperreality and Globalization: Culture in the age of Ronald McDonald. Journal of International Consumer Marketing, 8(3/4), 9-22.

Creswell, J. W. (2010). Designing and Conducting Mixed Methods Research, Sage Publication.

De Mooij, M. (2003). Convergence and divergence in consumer behavior: Implications for global advertising. International Journal of Advertising, 22, 189.

De Mooij, M. \& Hofstede, G. (2002). Convergence and divergence in consumer behavior: Implications for international retailing. Journal of Retailing, 78, 61-69.

Douglas, S. P. \& Yoran, W. (1987). The myth of globalization. The Columbia Journal of World Business, 22(4), 19-30.

Engledow, J. L., Hans, B. T. \& Helmut, B. (1975). The information seekers - across-cultural consumer elite. Advances in consumer research. Ed. Mary.

Gachunga, H. G. (2008). Impact of Globalization on the Human Resource Management in a developing Country: A Case Study of Kenya Public Corporations, 36.

Greener, S. (2008). Business Research Methods, Ventus Publishing APS, Copenhagen, 47-51.

Hassan, S. S. \& Coskun, S. A. (1994). The new frontiers of intermarket segmentation. Global marketing Perspectives and cases. Salah S. Hassan, and Roger D. Blackwell, 76-100. Fort Worth: The Dryden Press, Harcourt Brace College Publishers.

Hassan, S., Craft, S. \& Kortam, W. (2003). Understanding the new bases for global marketing segmentation. Journal of Consumer Marketing, 20(5), 446-62.

Jain, S. C. (1989). Standardization of international marketing strategy: Some research hypothesis. Journal of Marketing, 53(71).

Kale, S. H. \& Sudharshan, D. (1987). A strategic approach to international marketing. International Marketing Review, 3, 60-70.

Kolb, B. (2008). Marketing Research: A Practical Approach. A Perspective on Consumer Behavior, 2, 4-6.

Kotler, P. (1986). Global standardization - Courting danger. The Journal of Consumer Marketing, 3(2), 1315.

Kreutzer, R. T. (1988). Marketing mix standardization: An integrated approach in global marketing. European Journal of Marketing, 22(10), 19-30.

LeBlanc, R. P. \& Neil, C. H. (2001). Cross-cultural consumer decisions: Consideration sets - A marketing universal? Marketing Intelligence and Planning, 19(7), 500-506.

Levitt, T. (1983). The globalization of markets. Harvard Business Review, 2, 2-11.

Levitt, T. (1988). The pluralization of consumption. Harvard Business Review, 2, 8. 
Manrai, L. \& Ajay, M. (1996). Current issues in the cross-cultural and cross- national consumer research. Journal of International Consumer Marketing, 8(3/4), 9-22.

Ryans, J. K., Griffith, D. A. \& White, S. D. (2003). Standardization/adaptation of international marketing strategy: necessary conditions for the advancement of knowledge. International Marketing Review, 20(6), 588-603.

Shoham, A. (1995). Global marketing standardization. Journal of Global Marketing, 9(1/2), 91-119.

Ter-Hofstede, F., Steenkamp, J. B. \& Wedel, M. (1999). International market segmentation based on consumer-product relations. Journal of Marketing Research, 36, 1-17.

Usunier, J. C. (1999). Cultural aspects of international business negotiations. International business negotiations. Ed. Pervez Ghauri, and Jean-Claude Usunier, Amsterdam: Pergamon, 91-118.

Viswanathan, N. K. \& Divkson, P. R. (2007). The fundamentals of standardizing global marketing strategy. Emerald Group Publishing Limited International Marketing Review, 24(1), 46.

Walters, P. G. P. (1986). International Marketing policy: A discussion of the standardization construct and its relevance for corporate policy. Journal of International 330 Business Studies, 17(2), 55-69.

Waters, M. (2000). Globalization. 2nd Edition: 36-37. Retrieved from http://pol.atilim.edu.tr/files/kuresellesme/kitaplar/Globalization_keyideas.pdf.

Zou, S. \& Cavusgil, T. (2002). The GMS: A broad conceptualization of global marketing strategy and its effect on firm performance. Visit web site: impgroup.org/uploads/papers/5675.pdf. Journal of Marketing, 66(4), 40-57. 